für Dunkelrot unter der Dunkelkontrolle und die Werte für Hellrot plus Dunkelrot weit unter den Werten für Dunkelrot allein. Außerdem ändern sich die Relationen zwischen den Effekten der verschiedenen Lichtbehandlungen während der Versuchsdauer in einer momentan noch gänzlich undurchschaubaren Weise. Wir glauben, daß auch in diesem Fall die gewählten Bezugssysteme (Organ bzw. Trockengewicht) wenig geeignet sind, den Einfluß des Lichts auf die Dynamik der Nucleinsäuren zum
Ausdruck zu bringen. Jedenfalls sind die mitgeteilten Resultate mit der Theorie des Phytochroms insofern nicht verträglich, als sie nur deutbar sind, wenn man annimmt, daß sowohl $\mathrm{P}_{660}$ als auch $\mathrm{P}_{730}$ physiologisch aktiv sind und daß $\mathrm{P}_{730}$ in älteren Dunkelkeimlingen in erheblicher Konzentration vorhanden ist. Beide Annahmen sind durch die bisherigen Erfahrungen ${ }^{1}$ offenbar nicht gerechtfertigt.

Diese Arbeit wurde von der Deutschen For$\mathrm{s} c \mathrm{~h}$ ung $\mathrm{s}$ ge m e in s c h a f $\mathrm{t}$ unterstützt.

\title{
Isolation of Spherosomes with Lysosome Characteristics from Seedlings
}

\author{
Ph. Matile, J. P. Balz, E. Semadeni, and M. Jost \\ Department of General Botany, Swiss Federal Institute of Technology, Zurich \\ (Z. Naturforschg. 20 b, 693-698 [1965]; eingegangen am 20. Januar 1965)
}

\begin{abstract}
Fractionation of cell free extracts from corn and tobacco seedlings by density gradient centrifugation resulted in the isolation of two fractions containing acid hydrolases: protease, phosphatase, esterase and ribonuclease. In one fraction prospherosomes were the predominant cytoplasmic structures. The other fraction contained spherosomes in either free form or enclosed together with other structured material in membrane-bound vacuoles. These forms of isolated spherosomes are identified with corresponding structures observed in situ. It is concluded that the spherosomes represent the lysosome equivalent of higher plant cells. The vacuoles containing spherosomes, mitochondria and other structured elements are interpreted as digestion vacuoles corresponding to the cytolysomes of animal cells.
\end{abstract}

The spherosomes are cytoplasmic particles present in most cells of higher plants. Grieshaber ${ }^{1}$ has recently described their morphological properties, origin and development. A spherosome consists of an electron dense stroma surrounded by a single membrane; it represents a differentiated fragment of the endoplasmic reticulum (FrEY-WyssLIng et al. ${ }^{2}$, Geneves et al. ${ }^{3}$ ).

Very little is known of the chemical composition and the physiological function of the spherosomes since they have never been isolated. In many tissues they contain high amounts of lipids as concluded from appropriate staining and extraction procedures (Drawert and MIX ${ }^{4}, \mathrm{ZIEGLER}^{5}$ ). On the other hand the spherosomes can be stained with specific reagents

1 E. Grieshaber, Vjschr. Naturforsch. Ges. Zürich 109, 1 [1964].

2 A. Frey-Wyssling, E. Grieshaber, and K. Mühlethaler, J. Ultrastructure Res. 8, 506 [1963].

3 M. L. Geneves, A. Lance and M. R. Buvat, C. R. hebd. Séances Acad. Sci. 247, 2028 [1958].

${ }^{4}$ H. Drawert and M. Mix, Ber. dtsch. bot. Ges. 75, 128 [1962].

5 H. Ziegler, Z. Naturforschg. 8 b, 662 [1953].

${ }^{6}$ E. S. Perner, Biol. Zbl. 71, 43 [1952]. for protein $\left(\mathrm{PERNER}^{6}{ }^{6}, \mathrm{JAROSCH}^{7}\right)$. At least part of this protein has an enzyme character: acid phosphatase (Jensen ${ }^{8}$, Avers and King ${ }^{9}$, Walek-CzerNECKA ${ }^{10}$ ), and an unspecific esterase (W $W_{\text {ALEK-CZER- }}$ NECKA ${ }^{11}$ ) have been identified histochemically. Recently Olszewrsa and Gabara ${ }^{12}$ have localized a number of hydrolases in spherosomes present in the cell plate after mitosis. Moreover acid phosphatase has been sedimented from homogenates of onion seedlings and preliminary evidence has been presented that this enzyme is localized in a membranebound particulate component of the cell homogenate (Harrington and Altschul ${ }^{13}$ ).

These results indicate the presence of particles in plant cells which may resemble the lysosomes of

7 R. Jarosch, Protoplasma 53, 34 [1961].

8 W. A. Jensen, Amer. J. Bot. 43, 50 [1956].

9 C. J. Avers and E. E. King, Amer. J. Bot. 47, 220 [1960].

10 A. Walek-Czernecka, Acta soc. bot. Polonia 31, 539 [1962].

11 A. W alek-Czernecka, Acta soc. bot. Polonia 32, 405 [1963].

12 M. J. Olszzewska and S. Gabara, Protoplasma 54, 163 [1964].

13 J. F. Harrington and A. M. Altschul, Abstr. Federat. Proc. 22, 475 [1963]. 
animal cells with respect to hydrolytic enzymes. In order to examine the existence of such organelles in plant cells we have begun an extensive study using cell fractionation procedures with particular reference to hydrolases.

\section{Material and Methods}

Objects: Seeds of corn (Zea mays, variety Orla 266) were soaked in tap water for $48 \mathrm{hrs}$, sterilized in $2 \%$ $\mathrm{H}_{2} \mathrm{O}_{2}$ and germinated in the dark for $48 \mathrm{hrs}$ at $27^{\circ} \mathrm{C}$. Sterilized tobacco seeds (Nicotiana tabaccum, variety Alta) were plated on $2 \%$-agar in petridishes and exposed to light for $30 \mathrm{hrs}$. After induction of germination the seedlings were grown in the dark for $70 \mathrm{hrs}$ at $27^{\circ} \mathrm{C}$.

Cell fractionation. The corn seedlings were isolated from the remainder of the seed, cooled to $0{ }^{\circ} \mathrm{C}$ and ground in a mortar in the presence of washed sand and ice cold $20 \%(\mathrm{w} / \mathrm{v})$ sucrose containing $0,1-m$. Trisbuffer $\left(p_{\mathrm{H}} 7.1\right)$ and $1 \mathrm{mM}$ EDTA. The very small seedlings of tobacco were homogenized together with the seeds. The aggregation of cytoplasmic particles in extracts from tobacco seedlings was prevented by the addition of $0.1 \%$ of polyvinyl-pyrrolidone. After filtration of the homogenates through two layers of cheese cloth the first centrifugation $(10 \mathrm{~min}, 500 \mathrm{~g})$ removed the sand, cell debris, nuclei and starch. $1.4 \mathrm{ml}$ of the resulting cell free extract which was very turbid were layered on $4 \mathrm{ml}$ of a linear density gradient ranging from 20 to $50 \%(\mathrm{w} / \mathrm{v})$ sucrose ( $1 \mathrm{mM}$ EDTA). After centrifugation in a swinging bucket rotor SW 39 (Spinco model L ultracentrifuge) at $40^{\prime} 000 \mathrm{rpm}$ for 2.5 or $4.5 \mathrm{hrs}$. the bottoms of the tubes were punched and the outflowing content collected in 15 or 19 fractions.

Enzyme assays. Proteolytic activity was determined according to MATILE ${ }^{14}$. Acid phosphatase and esterase: the method of Seligman ${ }^{15}$ was modified; Diazoechtblau (gift of Rohner AG, Pratteln, Switzerland) was used as the coupling reagent for the $\alpha$-naphtol split from $\alpha$-naphtyl phosphate or -acetate. Ribonuclease: $0.1 \mathrm{ml}$ of enzyme was incubated with $0.9 \mathrm{ml}$ of buffered purified yeast RNA for $30 \mathrm{~min}$ at $37^{\circ} \mathrm{C}$. The reaction was stopped by the addition of uranylacetate-trichloracetic acid and the precipitated RNA centrifuged. The differences of extinctions at $260 \mathrm{~m} \mu$ between incubated and nonincubated samples were corrected for nonenzymatic degradation of RNA. Cytochrome oxidase was measured according to Nielsen and LehNinger ${ }^{16}$.

Protein was determined colorimetrically (Lowry et al. ${ }^{17}$ ). RNA was estimated by treatment of the fractions with $10 \%$ trichloracetic acid and subsequent hydrolysis of the precipitate with $5 \%$ perchloric acid

14 Рн. Matile, Naturwissenschaften 51, 489 [1964].

15 A. M. Seligman, J. biol. Chemistry 190, 7 [1951].

16 S. O. Nielsen and A. Lehninger, J. biol. Chemistry 215 , 555 [1955]. for 20 min at $90{ }^{\circ} \mathrm{C}$. The amount of RNA is expressed by the extinction of the hydrolysate at $260 \mathrm{~m} \mu$.

Electron microscopy. The method for the examination of tissues was the same as described by GriesHABER ${ }^{1}$. Isolated particles were fixed either in suspension with $1 \%$ buffered osmic acid, or spun into a pellet using an angle head rotor and fixed with glutaraldehyde (Sabatini et al. ${ }^{18}$ ). In the first case sucrose was dissolved in the fixative to make a concentration isotonic to the suspension to be fixed; after fixation $\left(12 \mathrm{hrs}, 4{ }^{\circ} \mathrm{C}\right)$ the fixed particles were centrifuged and the pellet dehydrated and embedded in EPON. In the second case the glutaraldehyde was washed out with several changes of phosphate buffer and the pellet postfixed with osmic acid. Oriented thin sections were treated according to Reynolds ${ }^{19}$ and examined in a Siemens Elmiskop I electron microscope.

\section{Results}

Properties of acid hydrolases. An acid protease present in the extracts of seedlings splits peptide bonds of denatured hemoglobin. The $p_{\mathrm{H}}$ optima of this reaction are 4.2 and 3.5 in preparations from corn and tobacco seedlings respectively; no substrate other than denatured protein is attacked; no hydrolysis of artificial substrates such as $\beta$-leucylor $\beta$-alanylnaphtylamide or $N$-acetyl-phenylalanine$\beta$-naphtylester was observed. The enzymes are therefore probably unspecific acid endopeptidases of a cathepsin type. The esterase activity is optimal at $p_{\mathrm{H}} 5.6$ though a second optimum beyond $p_{\mathrm{H}} 7$ is evident in tobacco seedlings. The naphtylacetate used for the determination of esterase acitivies is not suitable as a substrate at alkaline $p_{\mathrm{H}}$ values for reasons of nonenzymatic saponification. Acid phosphatase activity of seedlings exhibits maxima at two close $p_{\mathrm{H}}$ values of 5.0 and 6.5 for corn and 5.4 and 5.8 for tobacco. Acid ribonuclease is optimally active at $p_{\mathrm{H}} 6.0$.

Sedimentation of acid hydrolases from cell free extracts. Centrifugation of cell free extracts at high centrifugal forces ( $1 \mathrm{hr}, 105^{\prime} 000 \mathrm{~g}$ ) effects the sedimentation of a relatively high proportion of total acid hydrolase activity. For example 65\%, 40\% and $20 \%$ of protease-, ribonuclease, and phosphataseactivity are sedimentable in extracts of tobacco seedlings. These values are not very reliable however, since remarkable overrecovery of total hydrolase

17 O. H. Lowry, N. J. Rosebrough, A. L. FArr and R. J. Randall, J. biol. Chemistry 193, 265 [1951].

18 D. D. Sabatini, K. Bensch and R. J. Barnett, J. Cell Biol. 17, 19 [1963].

19 E. S. Reynolds, J. Cell Biol. 17, 208 [1963]. 
activity after separation of the particulate components from the soluble material indicates the possibility of an interaction between hydrolases and soluble factors. In fact the high speed supernatant contains an inhibitory factor for acid protease and phosphatase as demonstrated by determinations of sedimentable activities in the presence or absence of aliquots of supernatant soluble material.

Determinations of total sedimentable acid hydrolase activities were usually done with preparations sonicated prior to incubation. If sonication of the particle suspensions was omitted and the tonicity of the medium was maintained during incubation $(20 \%$ sucrose), very low activities were measured as compared with activities of sonicated controls. Moreover freezing and thawing of the suspensions prior to the enzyme assay increased the activities markedly. These results suggest that the acid hydrolases are localized in membrane bound cellular particles.

Density gradient centrifugation. In order to recognize the nature of the particulate cytoplasmic elements carrying acid hydrolases, cell free extracts from seedlings were submitted to density gradient centrifugation. The separation of cytoplasmic particles achieved by this method appears from the distribution of various enzymes along the sucrose gradient. The visual appearance of the gradients after centrifugation of the extracts is illustrated in Fig. 1. A series of bands can be observed. After

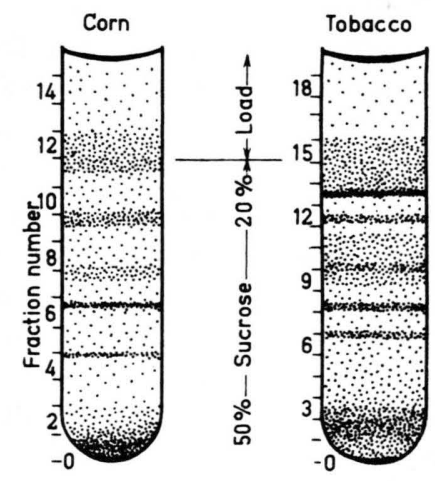

Fig. 1. Density gradient centrifugation of cell free extracts from corn and tobacco seedlings. Aspect of the linear sucrose density gradients after 4.5 (corn) and 2.5 (tobaco) hrs. of centrifugation.

$2.5 \mathrm{hrs}$. of centrifugation the particles from corn seedlings are located in zones of the gradient having equal densities; the positions of the bands are not altered if the time of centrifugation is extended to $4.5 \mathrm{hrs}$, though the bands are somewhat spharpened.
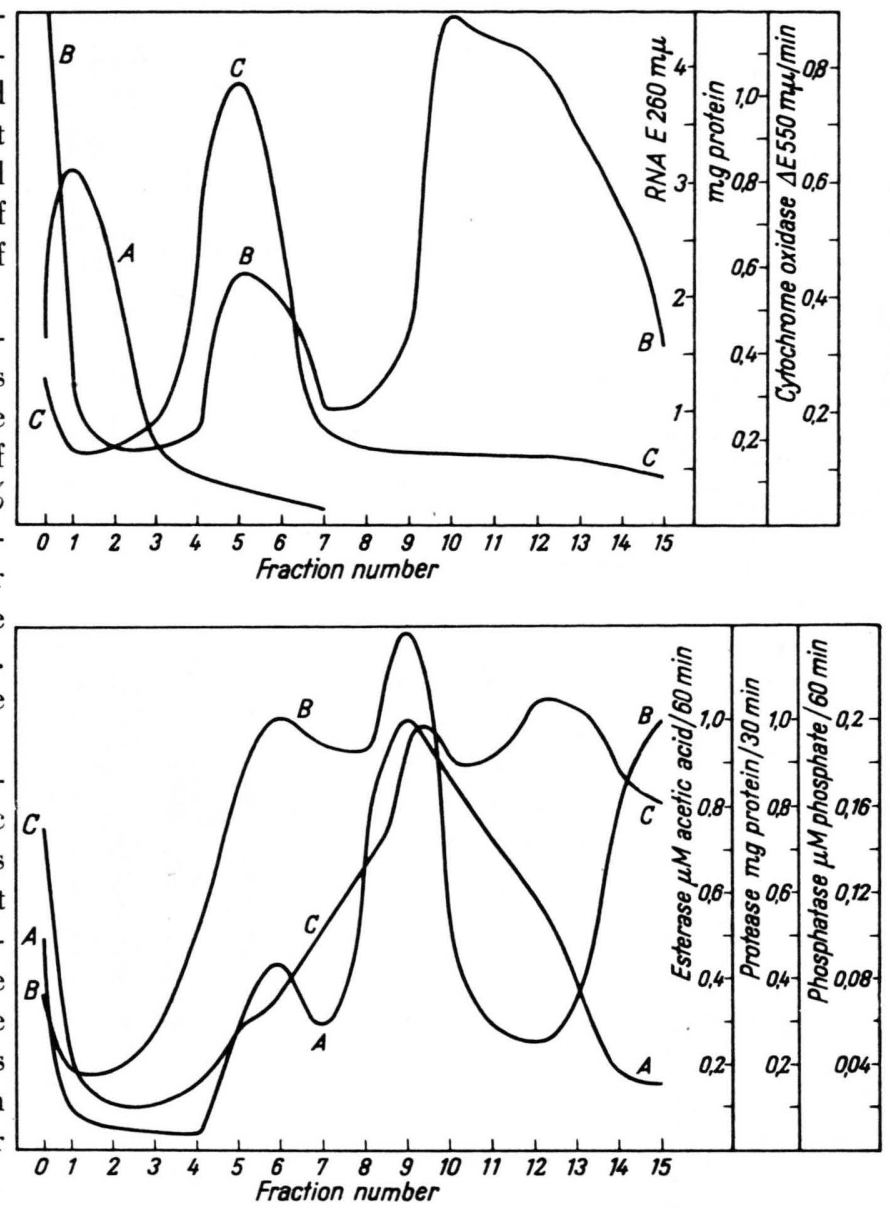

Fig. 2. Fractionation of cell free extracts from corn seedlings by density gradient centrifugation. a. Distribution of cytochrome oxidase activity (A), protein (B) and ribonucleic acid (C) . b. Distribution of acid protease (A), acid esterase (B) and acid phosphatase (C) activities.

Beginning from the bottom of the tube the first band contains the mitochondria as indicated by maxima of cytochrome oxidase activities in fraction 1 (corn) and fraction 2 (tobacco) respectively (distribution curves in Figs. $2 \mathrm{a}$ and $3 \mathrm{a}$ ). A minor peak of cytochrome oxidase occurs near the top of the sucrose gradient as shown in fraction 13 of Fig. 3 a. The relative activity located in this position varies considerably from one preparation to another. The significance of this peculiar distribution of cytochrome oxidase activity will be explained later.

The next band, fractions 4 and 5 from corn and 7 and 8 from tobacco coincides with the bulk of ribonucleic acid. Most probably the lightscattering material present in this zone of the gradient is not 

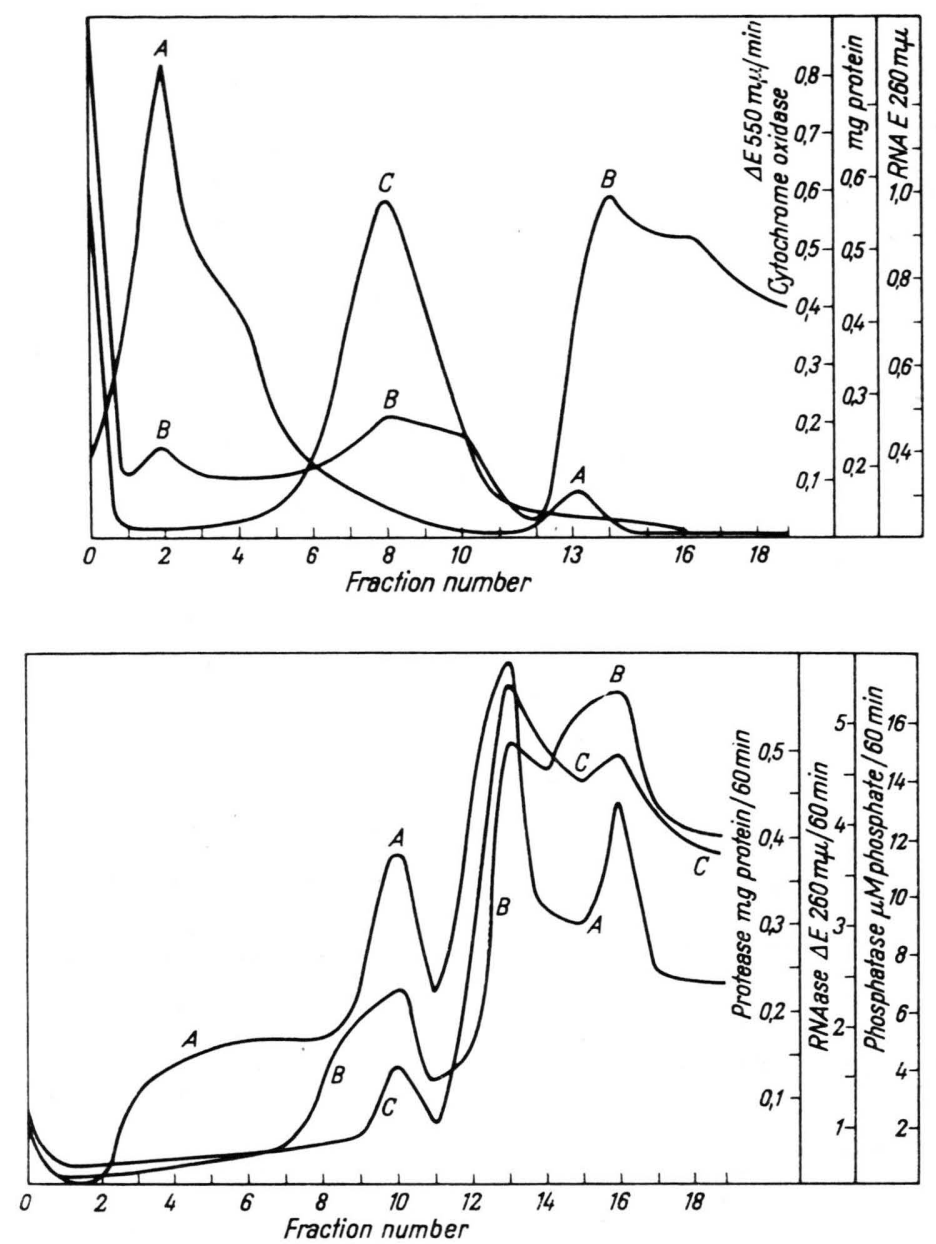

Fig. 3. Fractionation of cell free ectracts from tobacco seedlings by density gradient centrifugation. a. Distribution of cytochrome oxidase activity (A), protein (B) and ribonucleic acid (C). b. Distribution of acid protease (A), acid ribonuclease (B) and acid phosphatase (C) activities.

identical with ribosomes which are light transparent and therefore not visible. Moreover the RNA is not in density equilibrium but moves centrifugally from fraction 6 to fractions 4 and 5 (corn) between 2.5 and $4.5 \mathrm{hrs}$. of centrifugation. The question of whether the ribosomes are free or membranebound must remain open at the present time.

It is evident from Fig. $2 \mathrm{~b}$ that the third band, fraction 6 (corn), coincides with peaks of acid protease and esterase activity and with a shoulder of acid phosphatase activity. Since the particle containing these enzymes is in density equilibrium its relative density is $1.138 \mathrm{gcm}^{-3}$. It appears from the distribution curve of protein (Fig. 2 a) that it is relatively rich in protein. Similarly a culmination of peaks of acid hydrolases in fraction 10 shown in Fig. $3 \mathrm{~b}$ indicates the presence of corresponding particulate material in seedlings of tobacco. It is noteworthy that the shoulder of ribonuclease activity towards fraction 8 (RNA) indicates an association of this enzyme with the ribosomes. Again the fraction containing the acid hydrolases appears to be rich in protein as evident from the distribution of protein (Fig. 3 a) .

A second culmination of hydrolase activity peaks around fraction 9 (Fig. 2 b; corn) and fraction 13 (Fig. $3 \mathrm{~b}$; tobacco) indicates the presence of another particle containing these enzymes. Its density corresponds to approximately $27 \%$ sucrose, the density being $1.105 \mathrm{gcm}^{-3}$ (corn). Narrow bands are clearly visible at the respective heights of the gradients. Again the distribution curves of protein in Figs. 2 a and $3 \mathrm{a}$ demonstrate that these particles are relatively rich in protein. Furthermore the minor cytochrome oxidase peak represented in Fig. 3 a seems to be related to this material carrying acid hydrolases.

Between the two cytoplasmic components bearing acid hydrolases a further particle of corn seedlings forming a band in fractions 7 and 8 probably contains acid phosphatase as suggested by the distribution curve of this enzyme (Fig. 2 b). In tobacco extracts a particle with a similar density is present (Fig. 1) but seemingly contains no phosphatase (Fig. 3 b). Both extracts finally contain particulate elements of a density equal or lower than that of $20 \%$ sucrose. In the gradient this material assembles at the interphases of the sucrose gradients and the loaded extracts. Its nature is unknown.

It is evident from the distribution curves of the acid hydrolases that considerable portions of the total hydrolase activities are not attached to particles. Upon centrifugation these enzyme fractions remain among the soluble proteins of the cell free extracts. It is uncertain whether these obviously free enzyme molecules (fractions 11 to 15 , corn; 14 to 19, tobacco; Figs. $2 \mathrm{~b}$ and $3 \mathrm{~b}$ ) represent a fraction of intracellularly free hydrolases or originally bound hydrolases liberated from ruptured particles upon homogenization. The relative amounts of free and particulate hydrolases vary considerably from one preparation to another probably as a consequence of the manual, and therefore not completely reproducible, grinding of the tissues. It is likely that at least some of the soluble hydrolases (protease, ribo- 

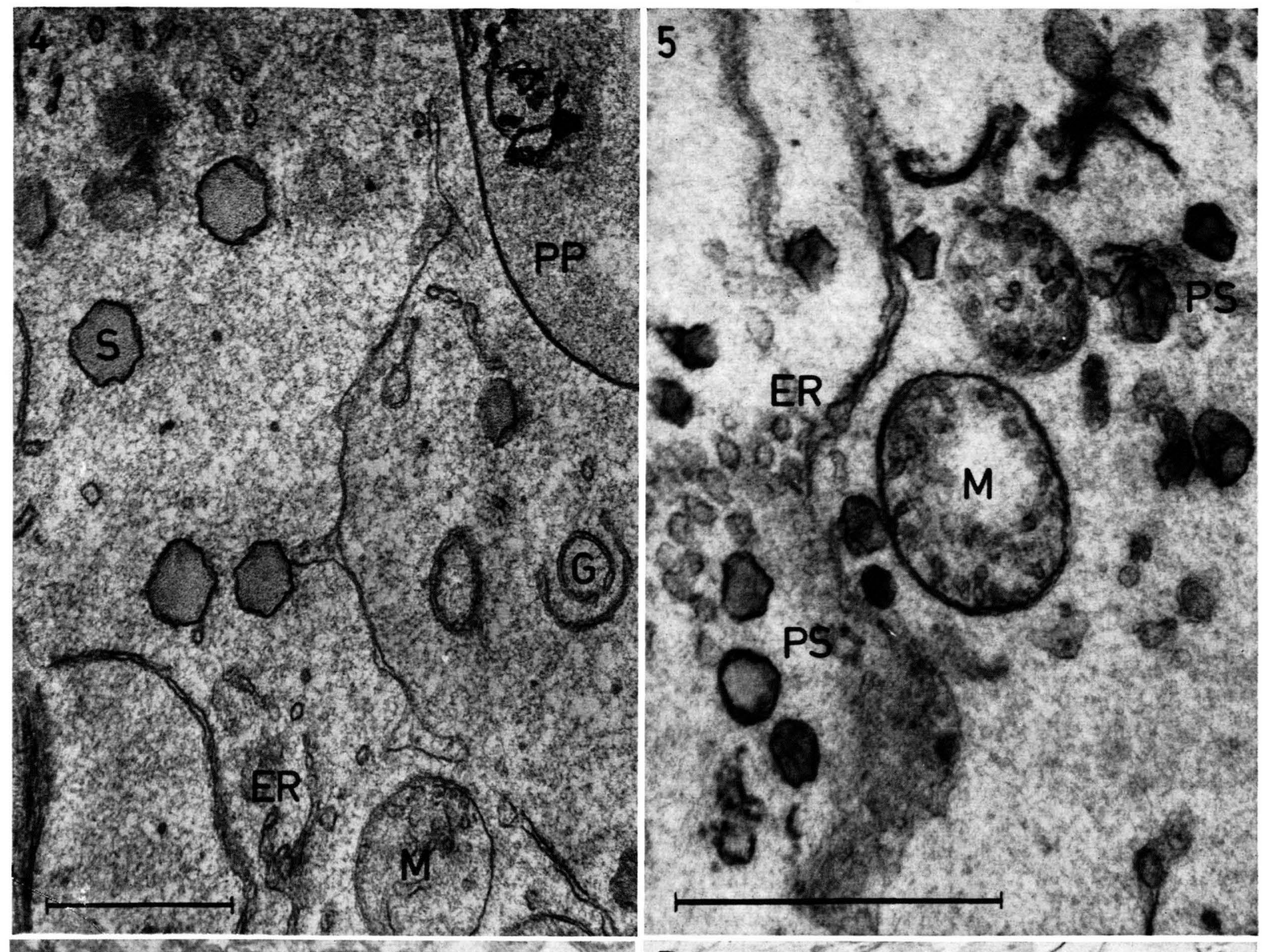

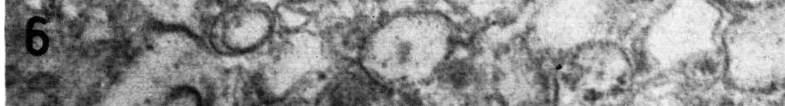

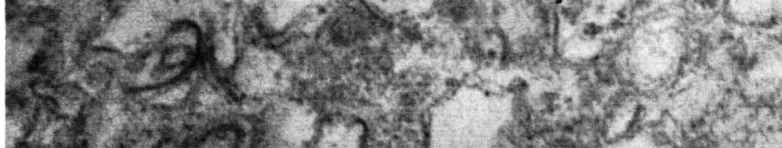

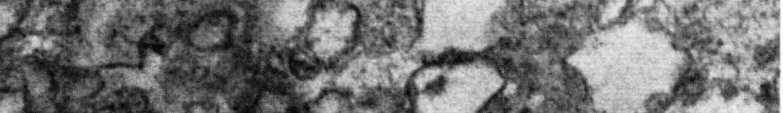

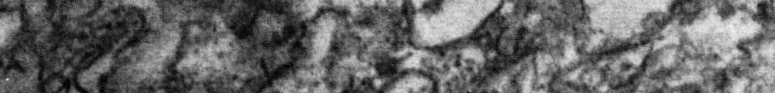

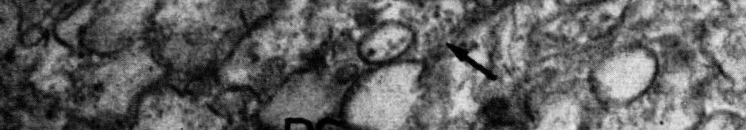

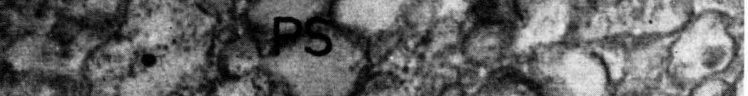

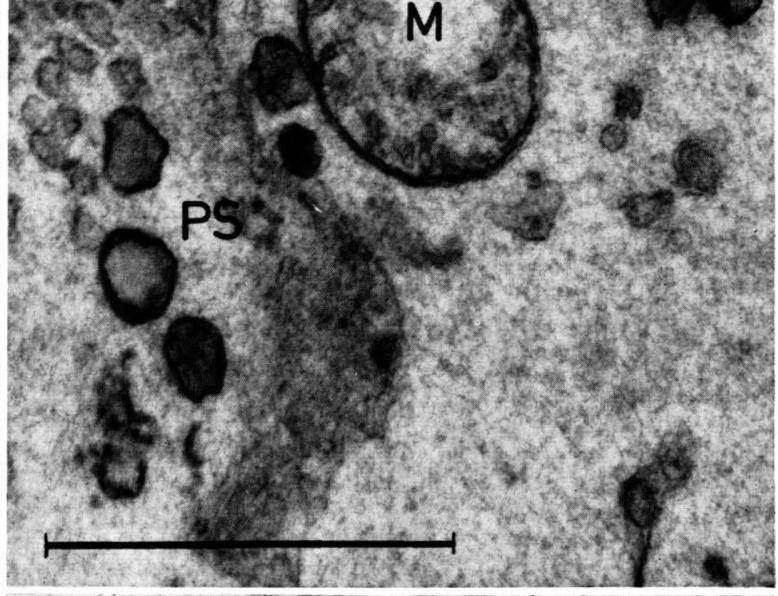

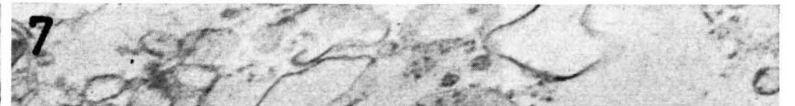

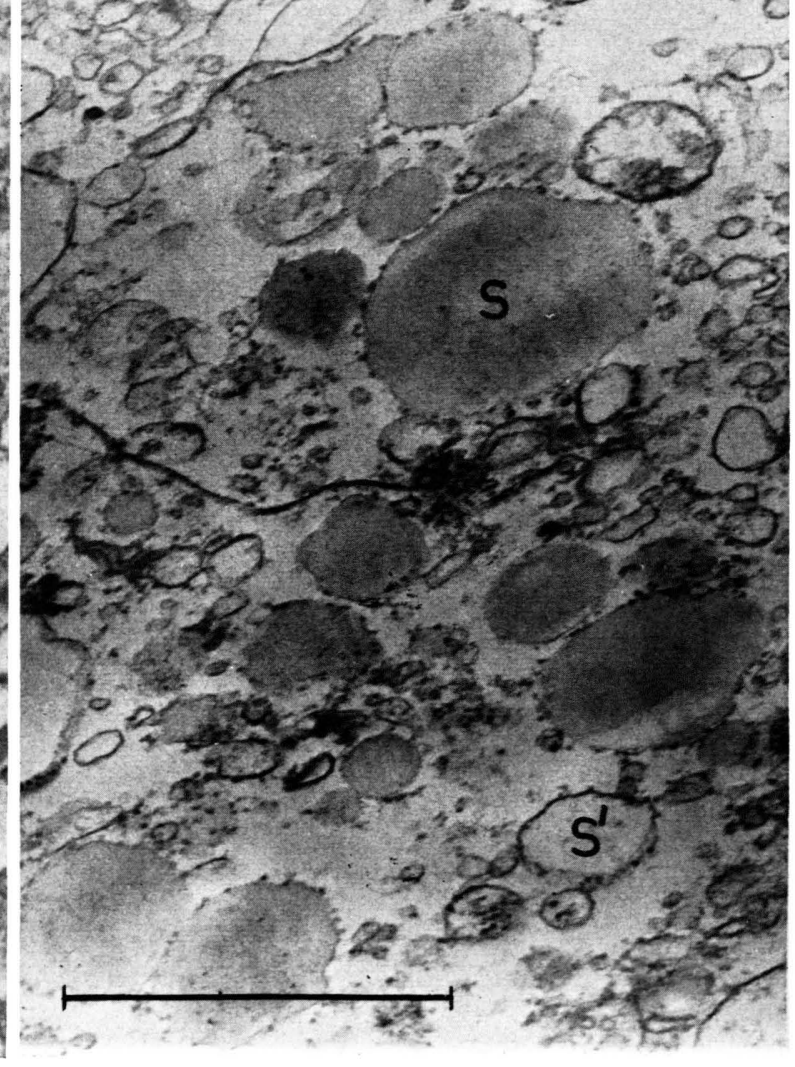

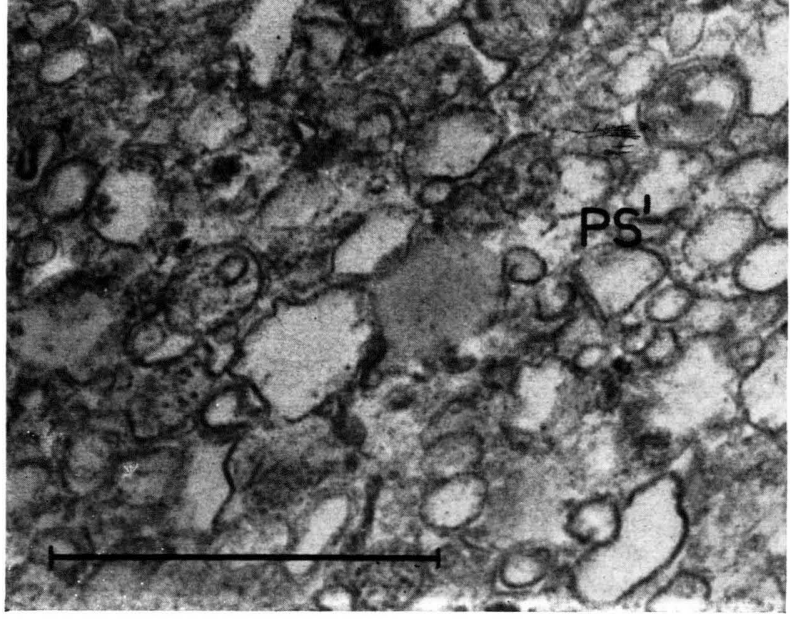




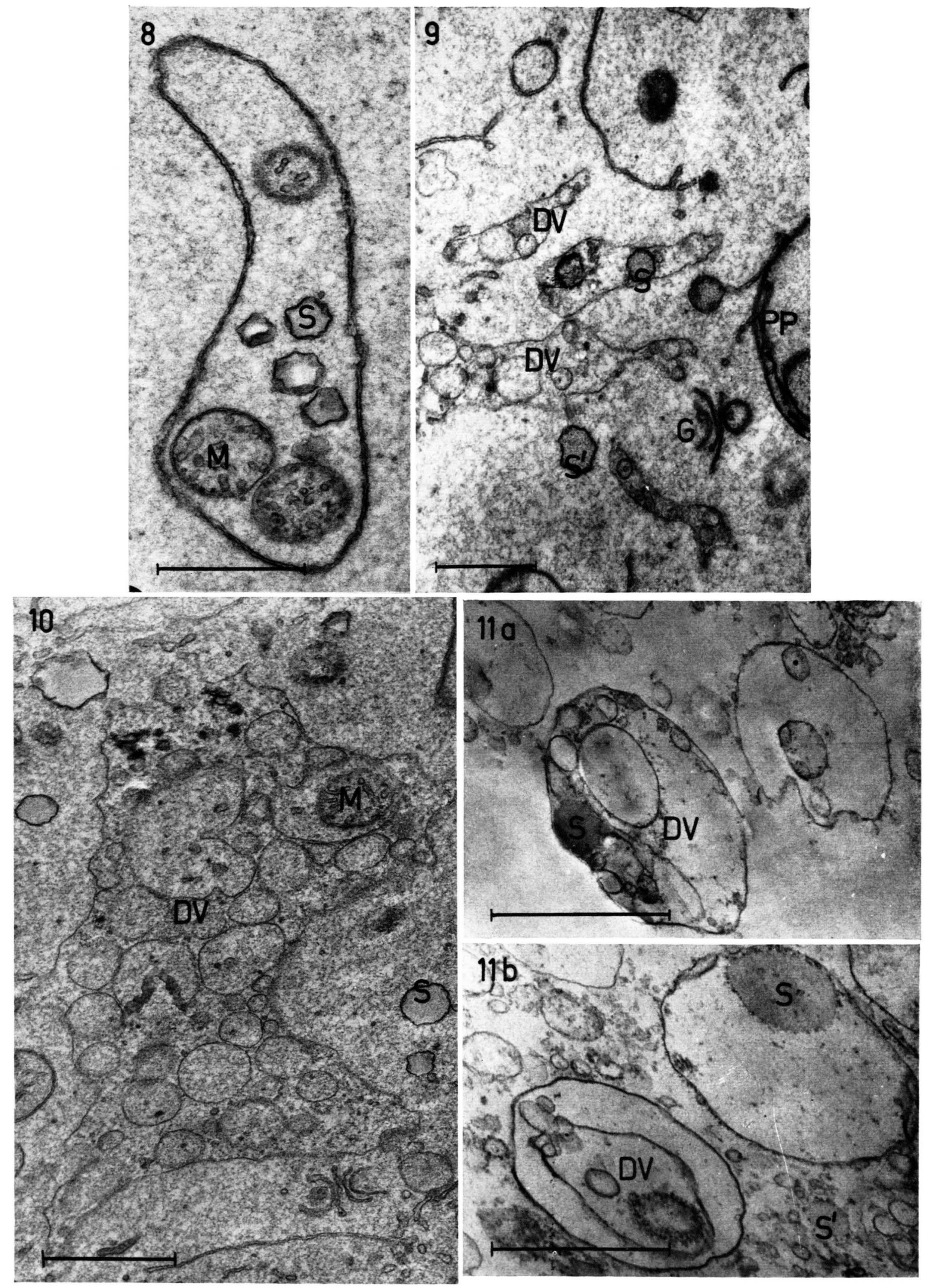


Fig. 4. Section of a cell from the coleorhiza of a corn seedling showing many spherosomes (S), mitochondria (M), filaments of the endoplasmic reticulum (ER), a $\mathrm{Golg}$ i complex $(\mathrm{G})$ and part of a proplastid (PP). (Fig. 4, 5, 8, 9 and 10 courtesy of E. Grieshaber.)

Fig. 5. Coleorhiza of a corn seedling: section of a cell showing filaments of endoplasmic reticulum (ER) in fragmentation and prospherosomes (PS) developing from the fragments.

Fig. 6. Section of a pellet obtained from particles with hydrolase activities (fraction 6 ; corn). The densely packed membrane vesicles with electron dense stroma propably represent prospherosomes (PS). Upon fixation many of them have lost their stroma (PS'). The dense granular material (arrow) is probably of ribosomal origin.

Fig. 7. Spherosomes (S) isolated by density gradient centrifugation of a cell free extract from corn seedlings (fraction 9). Some of the spherosomes have lost their stroma $\left(\mathrm{S}^{\prime}\right)$. Impurities in the form of small vesicular material are evident.
Fig. 8. Membrane limited cell compartment containing mitochondria (M) and spherosomes (S) in a cell of the corn coleorhiza. First stage of the formation of a digestion vacuole.

Fig. 9. Digestion vacuoles (DV) in a cell of the corn coleorhiza containing spherosomes (S) and many membranes possibly of mitochondrial origin. Free spherosomes (S'), a Golgi complex (G) and part of a proplastid (PP) are visible.

Fig. 10. Large digestion vacuole (DV) in a cell of the corn coleorhiza. It contains an intact mitochondrion (M) and many membrane vesicles probably representing remnants of digested mitochondria and other structured cell constituents.

Fig. $11 \mathrm{a}$ and b. Isolated digestion vacuoles obtained by density gradient centrifugation of a cell free extract from corn seedlings (fraction 9). Spherosomes (S) and membrane vesicles are visible within the digestion vacuole (DV). In the same fraction free spherosomes $\left(\mathrm{S}^{\prime}\right)$ are present. 
M. I. Elghamry, Biological Activity of Phytoestrogens. I. The thyroid uptake of $I^{131}$ together with its histology and hormones after $\beta$-sitosterol treatment (S.686)

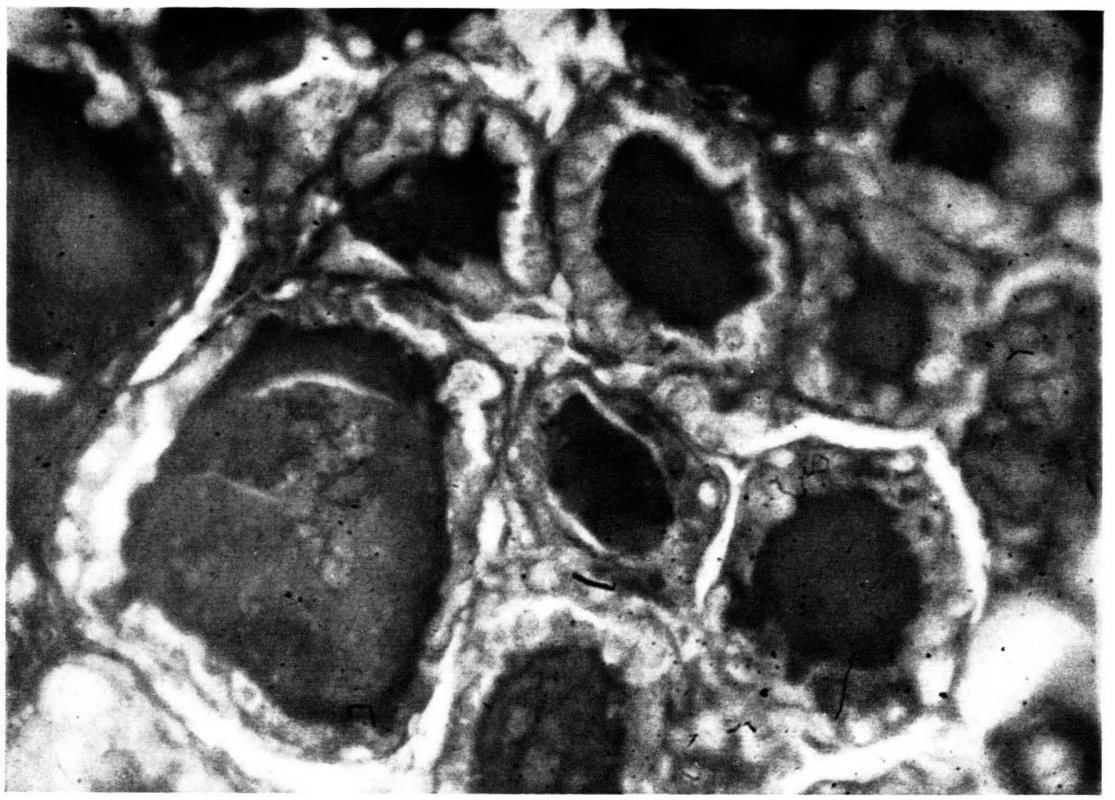

Fig. 1. The thyroid gland of an ovariectomized control showing flattened epithelial lining of the vesicles with accumulated colloid.

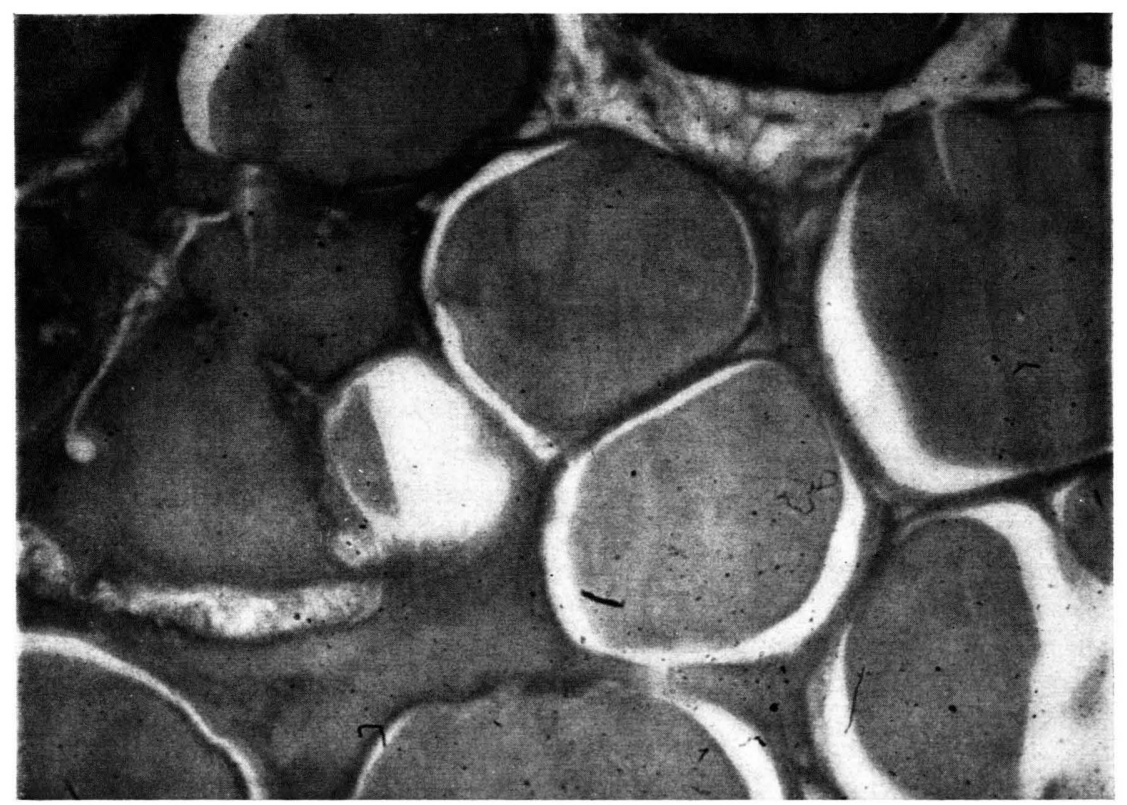

Fig. 2. The thyroid gland of an ovariectomized mice which received $10 \mu \mathrm{g}$. of $\beta$-sitosterol daily. Compare the epithelial height and the vesicular colloid with Fig. 1. 
nuclease) represent artifacts of the method applied. Acid esterase seemingly does not occur in a free form. Its distribution curve demonstrates a motion of a small fraction towards the centripetal end of the tube. It may be concluded from this behaviour that esterase is partially attached to a particle of low density, probably to lipid bodies.

Electron microscopy. In the cells examined biochemically spherosomes are present in considerable number (Fig. $4^{*}$ ). They are characterized by a relatively electron dense stroma, a single membrane envelope and a diameter of around $1 \mu$. The prospherosomes developing from filaments of the endoplasmic reticulum are smaller than the spherosomes $(0.15 \mu)$; as shown in Fig. 5 they are very numerous in certain regions of the cells. Electron microscopical examination of the two particulate fractions with acid hydrolase activities revealed the presence of spherosomes in the lighter and of small membrane limited particles in the heavier fraction. If the fractions were fixed with osmic acid in suspension a majority of empty vesicles could be observed. Prefixation with glutaraldehyde conserved the stroma of the particles much better as evident from Figs. 6 and 7 . In fraction 9 of corn extracts represented in Fig. 7 typical spherosomes are predominant structures. The particles of fraction 6 shown in Fig. 6 must be considered to represent prospherosomes since they contain the same enzymes as the spherosomes; they also have the same size as the prospherosomes observed in situ. The fraction is not pure however: at the bottom of the pellet the prospherosomes are intermixed with mitochondria.

Frequently in cells of the corn seedling spherosomes and mitochondria are found together in membrane limited compartments of the cytoplasm (Fig. 8). The envelope of such vacuoles is a double membrane, possibly a derivative of the endoplasmic reticulum. Significant structural changes within these vacuoles become manifest in electron micrographs such as shown in Fig. 9. The electron density of the included spherosomes decreases and the membranes seem to disappear. Sometimes huge vacuoles containing remnants of mitochondria and many mem-

\footnotetext{
* Figs. 4-11 s. table p. 696 a and b.

20 Ch. De Duve, in: Subcellular particles, Ronald Press, New York 1960, p. 128.

21 M. J. Fletcher andD. R. SANAdi, Biochim. biophysica Acta [Amsterdam] 51, 356 [1961].

22 A. B. Noviкoff, in: Developing cell systems and their control, Ronald Press, New York 1960, p. 167.
}

brane vesicles can be obseved (Fig. 10). They probably originate from smaller vacuoles by fusion.

These vacuoles represent compartments of intracellular digestion of cytoplasmic material since the acid hydrolases of the spherosomes contribute seemingly to their content effecting the breakdown of the vacuole bound structured elements. Fraction 9 of corn extracts containing the spherosomes also contains many of such vacuoles. In Fig. 11 sectors of the pellet with isolated vacuoles are shown. The presence of cytochrome oxidase in this fraction (compare Fig. 3 a) is probably due to mitochondrial material present in the digestion vacuoles. Concerning the envelope of the vacuoles both double and single membranes are observed; the digestive action of the spherosomal enzymes possibly involves a breakdown of the inner membrane. Since many of the digestion vacuoles have diameters exeeding $5 \mu$ it is possible that their integrity is lost during homogenization of the tissue. As a consequence free hydrolytic enzymes occur in the homogenate.

\section{Discussion}

The detection of the lysosome by DE DUve ${ }^{20}$ has given rise to many speculations concerning the physiological function of this cytoplasmic organelle. The lysosomal acid hydrolases are considered to play an important rôle in various digestion processes. It has been calculated that liver mitochondria undergo a rapid turnover, the halflife of these organelles being only approximately 10 days (F Letcher and SANADI ${ }^{21}$ ). Intracellular digestion of mitochondria has indeed been observed in both metabolically active and pathological cells; the digestion takes place in the so-called cytolysomes (NoviкofF ${ }^{22}$ ), which are digestion vacuoles containing hydrolases of lysosomal origin (Novikoff and Essner ${ }^{23}$, Ashrord and Porter ${ }^{24}$, Napolitano ${ }^{25}$ ). In fact preparations of purified lysosomes are capable of the extensive digestion of mitochondria and microsomes in vitro (SAwANT et al. ${ }^{26}$ ).

Cytplasmic structures seem to represent an architecture in the state of a dynamic equilibrium; for-

23 A. B. Novikoff and E. Essner, J. Cell Biol. 12, 198 [1962].

24 T. P. Ashrord and K. R. Porter, J. Cell Biol. 12, 198 [1962].

25 L. Napolitano, J. Cell Biol. 18, 478 [1963].

26 P. L. Sawant, I. D. Desai and A. L. Tappel, Biochim. biophysica Acta [Amsterdam] 85, 93 [1964]. 
mation and destruction occur simultaneously in a metabolically active cell, the pathway of the two processes being different. In necrotic tissues the digestion processes overcome the synthetic processes; lysosomes release their hydrolases into the cytoplasm and cause autolysis of the cells. Instead of a digestion limited to the membrane of the cytolysomes, a complete destruction of the cell occurs. Such processes have been observed in the regressing tail muscels of tadpoles $\left(\mathrm{W}_{\mathrm{EBER}}{ }^{27}\right.$ ), regression of Müllerian ducts during sexual differentiation in male chick embryos (Sснеiв ${ }^{28}$ ), liver necrosis following artificially produced anoxia (BEAUFAY et al. ${ }^{29}$ ) or poisoning (Dianzani ${ }^{30}$ ) and similar phenomena.

Our results indicate the presence in tissues of higher plants of organelles resembling the lysosomes of animal cells. These plant equivalents to the animal lysosomes are identical with spherosomes. Morphologically both organelles have a spherical shape, a single limiting membrane, and a more or less homogeneous, fine granular stroma. Biochemically they carry acid hydrolases; four hydrolytic enzymes have been localized in the spherosomes: acid protease, ribonuclease, phosphatase and esterase. Further studies may show that even more enzymes are present. Functionally both lysosomes and spherosomes play key rôles in intracellular digestion though investigations concerning the function of the spherosomes need completion.

There are minor differences between lysosomal and spherosomal properties. One difference is that the density of lysosomes $\left(1.22 \mathrm{gcm}^{-3}\right)$ is much higher than that of spherosomes $\left(1.105 \mathrm{gcm}^{-3}\right)$. It appears from previous studies on the spherosomes that they contain lipids ${ }^{1,4,5}$, wich may be responsible for their relatively low density. Prospherosomes

27 R. WEBER, Ciba Found. Sympos. on Lysosomes [1963], p. 282 .

28 D. Scheir, Ciba Found. Sympos. on Lysosomes [1963], p. 264 .

29 H. Beaufay, E. van Campenhout, and Ch. de Duve, Biochem. J. 73, 617 [1959].

30 M. U. Dianzani, Ciba Found. Sympos, on Lysosomes [1963], p. 335. probabely contain much less lipid as indicated by their higher density $\left(1.14 \mathrm{gcm}^{-3}\right)$. Another difference is that the esterase activity of lysosomes is readily lost upon isolation (HoLT ${ }^{31}$ ), whereas in spherosomes this activity seems to be attached strongly to the organelle.

The observation of intracellular digestion vacuoles in the metabolically very active tissues of corn seedlings supports the idea that the constituents of plant cells undergo a turnover similar to that of animal cells. Besides such intracellular digestion processes undoubtedly autolysis of tissues is a normal event during ontogenesis in higher plants. It is well known for example that prior to the abcission of the leaves of perennial plants autolysis of the cytoplasm of the leave cells takes place. Spherosomes may play an important rôle in this and similar autolytic processes. Furthermore, in seeds spherosomes may be involved in the mobilization of protein and other macromolecular storage substances during germination. A close morphological relationship between spherosomes and the vacuoles containing proteinous inclusion bodies in the aleuron cells of the wheat grain has been reported (Butrrose ${ }^{32}$ ). In corn seeds the scutellum is densely populated with spherosomes (Grieshaber ${ }^{33}$ ); this tissue is known to produce hydrolytic enzymes used to mobilize the reserves stored in the endosperm during germination. These enzymes may originate from the spherosomes.

In addition, the storage of lipids may represent still another type of differentiation of this organelle. This assumption points to a possible polymorphism of the spherosomes representing an analogy to the polymorphism of the lysosomes (DE DUVE ${ }^{34}$ ).

The present work has been supported by the $\mathrm{S}$ wis $\mathrm{s}$ $\mathrm{N}$ ational Science Found at i on and by Fabrique de cigarettes Turmac SA, Zurich.

31 S. J. Holt, Ciba Found. Sympos. on Lysosomes [1963], p. 114.

32 M. S. Buttrose, Austral. J. biol. Sci. 16, 768 [1963].

33 E. Grieshaber, Unpublished.

34 CH. DE Duve, in: Funktionelle und morphologische Organisation der Zelle. Springer Verlag Berlin 1963, p. 209. 